\title{
]jfis
}

\section{Meta-Heuristic Algorithms to Improve Fuzzy C-Means and K-Means Clustering for Location Allocation of Telecenters Under E-Governance in Developing Nations}

\author{
Rajan Gupta ${ }^{1}$, Sunil Kumar Muttoo ${ }^{1}$, and Saibal K. Pal ${ }^{2}$ \\ ${ }^{1}$ Department of Computer Science, University of Delhi, India \\ ${ }^{2}$ SAG Lab, Defence Research \& Development Organization (DRDO), Delhi, India
}

\begin{abstract}
The telecenter, popularly known as the rural kiosk or common service center, is an important building block for the improvement of e-governance in developing nations as they help in better citizen engagement. Setting up of these centers at appropriate locations is a challenging task; inappropriate locations can lead to a huge loss to the government and allied stakeholders. This study proposes the use of various meta-heuristic algorithms (particle swarm optimization, bat algorithm, and ant colony optimization) for the improvement of traditional clustering approaches (K-means and fuzzy C-means) used in the facility location allocation problem and maps them for the betterment of telecenter location allocation. A dataset from the Indian region was considered for the purpose of this experiment. The performance of the algorithms when applied to traditional facility location allocation problems such as set-cover, P-median, and the P-center problem was investigated, and it was found that their efficiency improved by $20 \%-25 \%$ over that of existing algorithms.
\end{abstract}

Keywords: Ant colony optimization, Bat algorithm, Common service center, E-governance, Fuzzy clustering, Meta-heuristic algorithm, Particle swarm optimization, Rural kiosk

\section{Introduction}

Received: Jan. 19, 2019

cCThis is an Open Access article distributed under the terms of the Creative Commons Attribution Non-Commercial License (http://creativecommons.org/licenses/ by-nc/3.0/, which permits unrestricted noncommercial use, distribution, and reproduction in any medium, provided the original work is properly cited.

E-governance refers to the use of technology for government operations that has been adopted all over the world. In e-governance, the services offered by the government are made available to the citizens of the country in an efficient and transparent manner. The challenge for the government originates from the changes in information flow and governance models facilitated by the information society [1]. Information and communication technology (ICT) can reduce corruption by promoting good governance, strengthening reform-oriented initiatives, reducing potential for corrupt behaviors, and enhancing relationships between the government, employees, and citizens [2-5]. E-governance is viewed as a positive channel that employs ICT to enhance trust in governments; it is considered to represent the public will in the information age [6].

Each country must develop a different strategy for the adoption of e-governance based on its resources and the level of e-readiness of its citizens. One of the important components in enhancing e-governance is the setup of telecenters that consist of basic ICT components. The 
centers are used for the communication between the government and citizens from remote/far-off areas. Developing nations require such telecenters in abundance as their infrastructure is in a growth stage and e-governance adoption is not prevalent yet. A developing nation such as India is one of the most significant nations in the modern world. India plans to spend billions of its currency on the setup of telecenters under its national egovernance plan. Therefore experimenting on data from the Indian region becomes important. Telecenters face various challenges that act as hindrances in the effective adoption of e-governance amongst the citizens of any nation. One such challenge is the precise detection of the most optimal location for the setup of the telecenters [7. 11$]$.

The telecenter location allocation problem is a considerably new research area in the field of location science. The main objective of telecenters is to locate these service points in such a manner that it is easily reachable, and the maximum population can avail its services. The telecenter location problem falls under the multi-facility location problem; furthermore, various associated problems have been defined w.r.t the telecenter. To begin with, the number of telecenters necessary to provide services to all the population nodes in an area must be determined. Next, each telecenter must be established at a point where its services are available within easy reach to customers to minimize travel cost. Moreover, the telecenter location must be close to densely populated nodes. This ensures that the maximum number of people from the cluster of population nodes can take advantage of it. Finally, the telecenter should be able to serve an optimal number of consumers within the densely populated area to minimize their waiting time. The scope of this study remains confined to discussing the location allocation of the telecenter.

\section{Literature Review}

There have been various attempts made to solve the problem of location allocation of telecenters in the past. However, there is room for modern techniques of analysis to be employed, and the scope for optimization still exists in this area of research. A few research studies using the schemes mentioned in the earlier paragraph have been noted and analyzed for the solution of the location allocation problem. One of the location allocation models for telecenters was studied and implemented in Turkey [12]. Turkey undertook an initiative to develop telecenters to reduce the digital divide and introduced public Internet access points. Telecenters were established with three main
objectives-Internet connection for the settlement, nearness of the locations, and electronic services on the Internet. Asik [13] defined various issues with the establishment of telecenters, and one of them was the selection of the hub for the settlement. Kitrinou et al. [14] presented a set cover-based model for the location choice of telecenters in the Aegean islands. Zolfani et al. [15] presented another case study based out of Iran for the performance evaluation of telecenters with the help of the following algorithms - the fuzzy analytical hierarchy process, the technique for order preference by similarity to ideal solution or TOPSIS-Grey method (a method based on the multi-criteria decision-making method), and the saw-G method (simple adaptive weighting with Grey relations). The study supplied an evaluation framework for the development of rural telecenters in Iran that can also be used for other countries. Another model of the common service center or the telecenter was studied by Marianov and Serra [16]. This model was based on minimizing consumer congestion and travel cost. The p-median constraint was used for the formulation of the problem solution. Apart from the telecenter location allocation, other facility location allocation applications were studied [17,-27].

The meta-heuristic algorithms are trusted in various other fields too, particularly for their efficiency. Thus, they are used extensively in various research applications. Harmony search was used with fuzzy C-means (FCM) to determine the aquifer parameters [28] and hybrid color image quantization [29]. Furthermore, it was used with K-means (KM) for document clustering [30] and the classification of polyester composites [31]. Harmony search was also used for the selection of features [32] and in wireless sensor networks [33]. Global harmony search was used for electric load forecasting [34] and in the detection of concealed weapons [35]. Even fuzzy logic has been recently applied in diverse application areas [36-39], which is a testament to its efficiency as well as its potential in the solution of other research problems. The relative importance of meta-heuristics has emerged in the solution of location allocation problems after an investigation into many of the algorithmic approaches used in its solution. Therefore, from the perspective of efficiency and applicability, these techniques appear to be stable enough to be used in the solution of the location allocation problem of telecenters. The vast number of articles do not deal with the optimization of telecenter location allocation problem. Therefore, there is a need for a telecenter location optimization problem solution that can help in solving a realistic telecenter model. Implementation of various meta-heuristic algorithms have been used in different applications of the location allocation problem. 
However, thus far they have not been employed in the solution of the telecenter location problem. There are three objectives of the current research work. They are as follows: to map the problem of telecenter location allocation in a developing nation; to determine the location of the telecenter in a given space of demand points; and to optimize the location of the telecenter in a given set of demand points using meta-heuristic algorithms.

\section{Methodology}

The approach to solve the existing problem has been divided into three phases. The first phase consists of problem mapping, the second phase consists of clustering the data points to find the cluster center, and the third phase consists of the application of meta-heuristic algorithms on the cluster center in order to optimize the location of the telecenter. The facility location allocation problem has been used to allocate the telecenter at an appropriate place such that the maximum number of people can use the services with minimum travel and cost. Mathematically, facility location allocation can be defined as follows:

$$
\text { Minimize } \sum_{p=1}^{m} \sum_{q=1}^{n} \text { dist }_{p, q} \text { weight }_{q}
$$

such that,

$$
\begin{aligned}
& \sum_{p=1}^{m} \text { Capacity }_{p}<=\text { Maximum Capacity } \\
& \sum_{q=1}^{n} \text { Demand }_{q}<=\text { Allocated Maximum Demand; }
\end{aligned}
$$

where $m$ is the number of facilities; $n$ is the number of demand points; dist $t_{p, q}$ is the distance between two points $p$ and $q$; weight $_{q}$ is the weight at demand point $q$.

\subsection{Phase 1}

The problem has been mapped as per the functionality of the telecenter and its working in a region. The basic concept is shown in Figure 1 with following objective function.

\section{Minimizing COST(Demand point, Telecenter Location) \\ $=$ Population (Demand Point) \\ * Travelling Cost(Demand point, Telecenter Location) \\ * Distance(Demand point, Telecenter Location).}

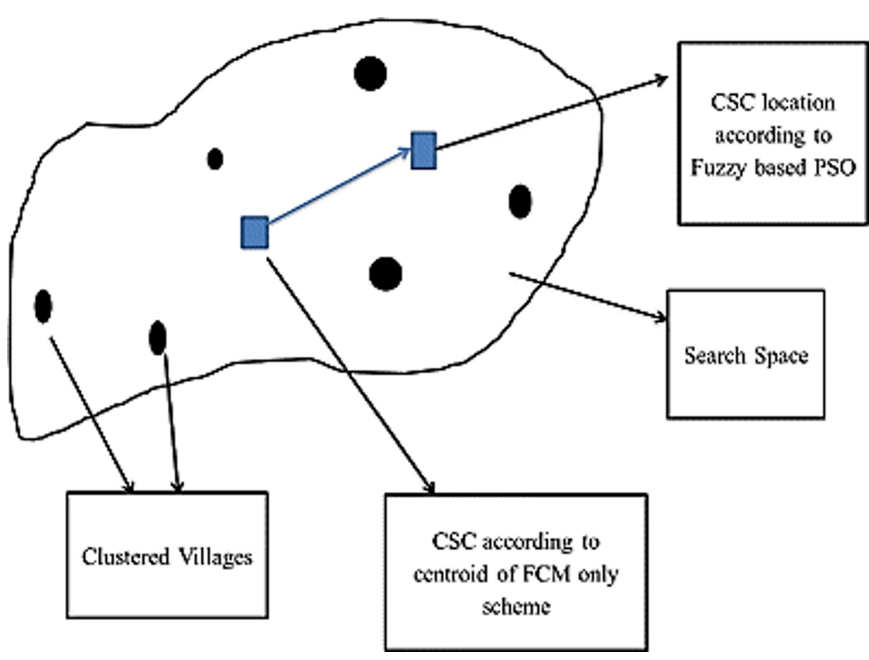

Figure 1. Overall conceptualization of the optimization of the telecenter in the search space.

\subsection{Phase 2}

Based on the objective function formulated, the demand points were clustered using the KM and the FCM algorithms. Among the different types of clustering schemes, the partition-based clustering method is widely used by researchers. The partitionbased clustering method includes two types of clustering schemes viz. FCM and KM clustering. A comparative analysis was carried out between both the algorithms and it was found that the execution time of FCM is lesser than that of the KM algorithm [40]. The fuzzy nature of the FCM algorithm makes it more computationally efficient [41]. In phase 2, the demand points were clustered into various groups using KM and FCM algorithms based on the distance between the points and the various cluster centers were obtained. For every region, three cluster centers were considered for experimental purposes while considering the latitudinal and longitudinal position of each demand point in the regions.

\subsection{Phase 3}

Once the demand points were clustered, the location of the telecenter was identified in different ways. The first choice was selecting a random location $(\mathrm{R})$. The second option was to select the center of the cluster as the location for the telecenter (C). The third option was the optimization of the cluster center using meta-heuristic algorithms such as particle swarm optimization (PSO), the bat algorithm (BA), and ant colony optimization (ACO) [42-44]. Moreover, the telecenter location was obtained from traditional models such as those using $\mathrm{P}$-center and $\mathrm{P}$ - 
median. Therefore, in phase 3, the cluster centers were selected and optimized using different optimization algorithms.

\subsection{Description of Existing Schemes}

The various schemes used in this study are KM clustering and FCM. Clustering is performed with three optimization schemes-PSO, ACO, and the BA. KM is one of the simplest forms of clustering that creates k-clusters from the given set of points based on their proximity to the cluster center, calculated via obtaining a mean of the points. At the end of various iterations, each point is allocated to only one cluster. For this reason, it is also known as a hard clustering technique. On the other hand, FCM is a soft clustering technique, which allows one point to be a part of more than one cluster. Fuzzy logic is applied while creating the clusters and while allocating points to various clusters. PSO, ACO, and BA are nature-inspired algorithms based on the behavior of different creatures on this earth. PSO is based on the food-search behavior of bees that work at different speeds in different positions to find food. BA is based on the behavior of bats that find their prey at night using supersonic waves. ACO is based on the behavior of a colony of ants moving in search of food in a particular direction. All these techniques optimize group behavior based on specific features and yield the most optimal location out of the given set of options where food may be found.

\subsection{Experimental Setup}

For experimental purposes, the data set has been taken from the villages of four different regions of India. Because India is adopting the e-governance implementation rapidly, and is climbing the United Nation's e-governance development index swiftly, it is a good candidate to consider for telecenter allocation. Moreover, a huge budget has been allocated by India under the National E-Governance Plan for allocation of telecenters in the rural areas of the country. The code has been implemented using MATLAB \& LINGO software on a Dell Inspiron 15R Machine with an Intel Core i5 processor, and a 64-bit operating system with 500 GB HDD and 4 GB of RAM.

\subsection{Parameters for the Optimization Algorithms}

There were different parameters used for the different algorithms investigated in the current study. In KM, the value of $k$ was set to be 12 , because three clusters were formed from four different regions and a 100 iterations were employed. In FCM, the fuzziness coefficient was set to 2 and the number of iterations was maintained at 100. In PSO, the initial swarm size was set to be 100 , the number of iterations was 100 and the accelerations coefficients were initialized to 0.5 each. In BA, the population size was 100 , number of iterations was 100 , and the rates for loudness and the pulse rate were set to be 0.1 each. In ACO, the initial colony size was assigned a value of 100 , the number of iterations was 100 , and the alpha-beta parameters were each assigned a value of 3 .

\section{Results}

The cost comparison, derived from the objective function via the use of different techniques is shown in Table 1. Overall 72 demand points were considered which were grouped into 12

Table 1. Cost comparison for various techniques implemented standalone and in combination for different regions

\begin{tabular}{lccccc}
\hline \multicolumn{1}{c}{ Algorithm } & R1 & R2 & R3 & R4 & Total \\
\hline KM-R & 33825 & 45835 & 39990 & 20109 & 139759 \\
KM-C & 23465 & 24957 & 30234 & 16784 & 95440 \\
\hline FCM-R & 32788 & 44830 & 38997 & 20023 & 136639 \\
FCM-C & 22996 & 23981 & 29092 & 15971 & 92042 \\
FCM-PSO & 21870 & 22317 & 28454 & 13189 & 85832 \\
FCM-Bat & 20727 & 19665 & 26627 & 12816 & 79837 \\
FCM-ACO & 21124 & 20785 & 27632 & 12980 & 82521 \\
P-center & 68470 & 45120 & 39018 & 14065 & 166673 \\
P-median & 22770 & 25010 & 38990 & 14580 & 101350 \\
\hline
\end{tabular}


clusters across four regions- $\mathrm{R} 1, \mathrm{R} 2, \mathrm{R} 3$, and R4. It is obvious that clustering schemes that have been optimized using various meta-heuristic techniques yield better results because their cost functions have lower values. The location allocation solution using traditional models such as P-center and P-median are far too expensive. Even the KM clustering algorithm was expensive as compared to the FCM clustering algorithms, therefore, metaheuristic schemes were only used to optimize the center of FCM based clusters.

$\mathrm{R} 1-\mathrm{R} 4$ are four different regions under the study: KM-R, $\mathrm{K}$-means clustering with random allocation; KM-C, K-means clustering with centroid; FCM-R, fuzzy C-means clustering with random allocation; FCM-C, fuzzy C-means clustering with centroid; FCM-PSO, fuzzy C-means clustering with particle swarm optimization for optimization of center; FCM-ACO, fuzzy C-means clustering with ant colony optimization for optimization of center; note that values are approximate and are calculated for 100 iterations.

The experiment was conducted over 100-15, 000 iterations. The statistical properties of the values for the objective function were observed over the different iterations. The objective function value was optimized in less than 1,000 iterations and very few variations were exhibited over 15, 000 iterations. Therefore, a convergence of the results was observed over a certain number of iterations. Table 2 shows the statistical properties of the meta-heuristic based techniques used for the optimization.

Even the worst value of the three schemes from Table 2 were found to be better than the best values achieved for normal FCM and KM techniques and traditional P-center and P-median based models. Of the three meta-heuristic schemes, the BA was found to be better than PSO and ACO. The validity of the new techniques can be attributed to the fact that a better objective function has been obtained as compared to that in previously used traditional techniques. Moreover, the clusters

Table 2. Statistical measures of techniques for total cost of four regions over repeated experimentation (approx. values)

\begin{tabular}{lrrc}
\hline & $\begin{array}{c}\text { FCM- } \\
\text { PSO }\end{array}$ & $\begin{array}{c}\text { FCM- } \\
\text { Bat }\end{array}$ & $\begin{array}{c}\text { FCM- } \\
\text { ACO }\end{array}$ \\
\hline Mean & 21458 & 20047 & 21004 \\
Standard deviation & 6205 & 6104 & 6139 \\
Minimum & 20100 & 19649 & 200455 \\
Maximum & 24623 & 22432 & 23985 \\
Range & 4523 & 2783 & 3940 \\
\hline
\end{tabular}

formed had low variability and appropriate cumulative intracluster distance. The results were improved over those of the existing schemes of P-median and P-center, while exclusive usage of clustering schemes proved to be more expensive for the objective function. Similar improved results were observed in the case of a combination of fuzzy-logic based clustering and an application of meta-heuristic algorithms in different areas [28-35]. This validates the findings of the current study. The use of optimization algorithms reduced the cost of the objective function over that resulting from the employment of standalone clustering techniques. Such an improvement has been noted in other areas as well [45].

\section{Conclusion}

The problem of allocating telecenters under the e-governance infrastructure was solved in this study. Various clustering and meta-heuristic schemes were used to find the optimized location of the telecenter. It is concluded that a combination of clustering and evolutionary schemes such as PSO, Bat, and ACO enhances the performance of the location allocation algorithm of the telecenter. Various researchers in the past have used P-center and P-median approaches to solve telecenter location allocation; however, they are costly techniques and the optimizations are more efficiently carried out using different strategies as suggested in this study. The cost of infrastructure can be reduced using the proposed techniques and citizens can be better engaged via the telecenters setup by the governments of developing nations. Because the developing nations have limited resources and revenues, a solution to the problem of allocating the infrastructure in the most efficient manner possible is helpful.

This work makes a few specific research contributions to the literature in its field of study. Although location optimization has attracted a lot of attention from researchers, the telecenter location allocation optimization model is considerably novel in this research area and demands a thorough investigation. To the best of our knowledge, there has not yet been a widespread application of meta-heuristic algorithms in combination with clustering to determine the optimal location of telecenters. Therefore, the addition of this work to the literature of e-governance and evolutionary computing will be helpful for the various stakeholders. Specifically, the application of $\mathrm{ACO}$ and Bat has not been reported upon in the literature with respect to telecenter location allocation. Moreover, the inherent property of the optimization scheme to focus on the most appro- 
priate point has been used for the allocation strategy; to date, this property has not been exploited in the field of telecenter location allocation. Mapping of the problem of locating a telecenter in a developing nation such as India has not been carried out effectively in the past. Thus, this study contributes to the literature from a problem mapping perspective in a relatively new application area. There is scope for future research based upon this study. Such research should include the implementation of various other meta-heuristic schemes such as harmony search, honeybee search etc., and the comparison of the results from these novel schemes against those of traditional approaches and already available meta-heuristic schemes.

\section{Conflict of Interest}

No potential conflict of interest relevant to this article was reported.

\section{References}

[1] M. Janssen and E. Estevez, "Lean government and platform-based governance: doing more with less," Government Information Quarterly, vol. 30(Supplement 1), pp. S1-S8, 2013. https://doi.org/10.1016/j.giq.2012.11. 003

[2] I. Ropke, T. H. Christensen, and J. O. Jensen, "Information and communication technologies: a new round of household electrification," Energy Policy, vol. 38, no. 4, pp. 1764-1773, 2010. https://doi.org/10.1016/j.enpol.2009. 11.052

[3] J. C. Bertot, P. T. Jaeger, and J. M. Grimes, "Using ICTs to create a culture of transparency: E-government and social media as openness and anti-corruption tools for societies," Government Information Quarterly, vol. 27, no. 3, pp. 264-271, 2010. https://doi.org/10.1016/j.giq.2010.03.001

[4] B. Gupta, S. Dasgupta, and A. Gupta, "Adoption of ICT in a government organization in a developing country: an empirical study," The Journal of Strategic Information Systems, vol. 17, no. 2, pp. 140-154, 2008. https://doi.org/ 10.1016/j.jsis.2007.12.004

[5] M. Yildiz, "E-government research: reviewing the literature, limitations, and ways forward," Government Information Quarterly, vol. 24, no. 3, pp. 646-665, 2007. https://doi.org/10.1016/j.giq.2007.01.002
[6] V. Pina, L. Torres, and B. Acerete, "Are ICTs promoting government accountability? A comparative analysis of egovernance developments in 19 OECD countries," Critical Perspectives on Accounting, vol. 18, no. 5, pp. 583-602, 2007. https://doi.org/10.1016/j.cpa.2006.01.012

[7] I. Rega, S. Vannini, E. Fino, and L. Cantoni, "Exploring the meanings of community multimedia centers in Mozambique: a social representation perspective," Information Technologies \& International Development, vol. 9, no. 4, pp. 35-54, 2013.

[8] G. C. Bonadia, I. M. A. Avila, C. M. Ogushi, and G. M. de Holanda, "Modeling the acceptance and use of telecenters in Brazil," Journal of Technology Management \& Innovation, vol. 2, no. 4, pp. 86-97, 2008.

[9] A. Dolgui, G. Morel, and C. E. Pereira, Information Control Problems in Manufacturing 2006: Proceedings of the 12th IFAC Symposium on Information Control Problems in Manufacturing (INCOM'2006). Oxford, UK: Elsevier Science, 2006.

[10] M. Junger and G. Reinelt, Facets of Combinatorial Optimization. Berlin: Springer, 2013.

[11] K. Prasad, "E-governance policy for modernizing government through digital democracy in India," Journal of Information Policy, vol. 2, pp. 183-203, 2012. http: //doi.org/10.5325/jinfopoli.2.2012.0183

[12] O. Asik, "Location optimization to determine telecenter network in rural Turkey," PhD dissertation, Cornell University, Ithaca, NY, 2014.

[13] O. Asik, "Use of information and communication technologies for integrated rural development in Turkey," Planning Expertise Thesis, State Planning Organization, Ankara, 2009.

[14] E. Kitrinou, A. Kolokolov, and L. Zaozerskaya, "The location choice for telecenters in remote areas. The case of the Aegean islands," in Proceedings of the 2nd International Workshop DOM-2004 (Discrete Optimization Methods in Production and Logistics), Omsk - Irkutsk, Russia, 2004, pp. 61-65.

[15] S. H. Zolfani, M. Sedaghat, and E. K. Zavadskas, "Performance evaluating of rural ICT centers (telecenters), applying fuzzy AHP, SAW-G and TOPSIS Grey, a case 
study in Iran," Technological and Economic Development of Economy, vol. 18, no. 2, pp. 364-387, 2012. https://doi.org/10.3846/20294913.2012.685110

[16] V. Marianov and D. Serra, "Location of multiple-server common service centers or facilities, for minimizing general congestion and travel cost functions," International Regional Science Review, vol. 34, no. 3, pp. 323-338, 2011. https://doi.org/10.1177\%2F0160017611403738

[17] M. T. Shourijeh, M. Kermanshah, A. R. Mamdoohi, A. Faghri, and K. Hamad, "A mathematical optimization model for locating telecenters," Applied Mathematics, vol. 3, no. 3, pp. 251-263, 2012. http://dx.doi.org/10.4236/am. 2012.33040

[18] L. Yang, B.F. Jones, and S. H. Yang, "A fuzzy multiobjective programming for optimization of fire station locations through genetic algorithms," European Journal of Operational Research, vol. 181, no. 2, pp. 903-915, 2007. https://doi.org/10.1016/j.ejor.2006.07.003

[19] U. Bhattacharya, J. R. Rao, and R. N. Tiwari, "Fuzzy multi-criteria facility location problem," Fuzzy Sets and Systems, vol. 51, no. 3, pp. 277-287, 1992. https://doi.org/ 10.1016/0165-0114(92)90018-Y

[20] M. Sakawa, K. Kato, H. Sunada, and T. Shibano, "Fuzzy programming for multiobjective $0-1$ programming problems through revised genetic algorithms," European Journal of Operational Research, vol. 97, no. 1, pp. 149-158, 1997. https://doi.org/10.1016/S0377-2217(96)00023-9

[21] G. H. Tzeng and Y. W. Chen, "The optimal location of airport fire stations: a fuzzy multi?objective programming and revised genetic algorithm approach," Transportation Planning and Technology, vol. 23, no. 1, pp. 37-55, 1999. https://doi.org/10.1080/03081069908717638

[22] C. T. Chen, "A fuzzy approach to select the location of the distribution center," Fuzzy Sets and Systems, vol. 118, no. 1, pp. 65-73, 2001. https://doi.org/10.1016/S01650114(98)00459-X

[23] U. Diwekar, Introduction to Applied Optimization. Dordrecht: Kluwer Academic Publisher, 2003.

[24] O. Berman and D. Krass, "The generalized maximal covering location problem," Computers \& Operations Research, vol. 29, no. 6, pp. 563-581, 2002. https://doi.org/10.1016/ S0305-0548(01)00079-X
[25] J. M. Diaz-Banez, J. A. Mesa, and A. Schobel, "Continuous location of dimensional structures," European Journal of Operational Research, vol. 152, no. 1, pp. 22-44, 2004. https://doi.org/10.1016/S0377-2217(02)00647-1

[26] M. X. Goemans and M. Skutella, "Cooperative facility location games," Journal of Algorithms, vol. 50, no. 2, pp. 194-214, 2004. https://doi.org/10.1016/S0196-6774(03) 00098-1

[27] C. E. G?ndogdu, "Suitable location selection optimization for shopping centres and Geographical Information System (GIS)," China-USA Business Review, vol. 10, no. 8, pp. 711-718, 2011.

[28] M. T. Ayvaz, "Simultaneous determination of aquifer parameters and zone structures with fuzzy c-means clustering and meta-heuristic harmony search algorithm," $A d$ vances in Water Resources, vol. 30, no. 11, pp. 2326-2338, 2007. https://doi.org/10.1016/j.advwatres.2007.05.009

[29] A. Khaled, R. F. Abdel-Kader, and M. S. Yasein, "A hybrid color image quantization algorithm based on kmeans and harmony search algorithms," Applied Artificial Intelligence, vol. 30, no. 4, pp. 331-351, 2016. https://doi.org/10.1080/08839514.2016.1169049

[30] M. Mahdavi and H. Abolhassani, "Harmony K-means algorithm for document clustering," Data Mining and Knowledge Discovery, vol. 18, no. 3, pp. 370-391, 2009. https://doi.org/10.1007/s10618-008-0123-0

[31] F. Pashmforoush, M. Fotouhi, and M. Ahmadi, "Acoustic emission-based damage classification of glass/polyester composites using harmony search k-means algorithm," Journal of Reinforced Plastics and Composites, vol. 31, no. 10, pp. 671-680, 2012. https://doi.org/10.1177\% 2F0731684412442257

[32] C. Cobos, E. Leon, and M. Mendoza, "A harmony search algorithm for clustering with feature selection," Revista Facultad de Ingenier? a Universidad de Antioquia, vol. 2010, no. 55, pp. 153-164, 2010.

[33] D. C. Hoang, P. Yadav, R. Kumar, and S. K. Panda, S. K. ?Real-time implementation of a harmony search algorithm-based clustering protocol for energy-efficient wireless sensor networks," IEEE Transactions on Industrial Informatics, vol. 10, no. 1, pp. 774-783, 2014. https://doi.org/10.1109/TII.2013.2273739 
[34] Y. Chen, W. C. Hong, W. Shen, and N. Huang, "Electric load forecasting based on a least squares support vector machine with fuzzy time series and global harmony search algorithm," Energies, vol. 9, no. 2, article no. 70, 2016. https://doi.org/10.3390/en9020070

[35] N. J. Hussein, F. Hu, and F. He, "Multisensor of thermal and visual images to detect concealed weapon using harmony search image fusion approach," Pattern Recognition Letters, vol. 94, pp. 219-227, 2017. https: //doi.org/10.1016/j.patrec.2016.12.011

[36] M. Rabah, A. Rohan, and S. H. Kim, "Comparison of position control of a gyroscopic inverted pendulum using PID, fuzzy logic and fuzzy PID controllers," International Journal of Fuzzy Logic and Intelligent Systems, vol. 18, no. 2, pp. 103-110, 2018. https://doi.org/10.5391/IJFIS. 2018.18.2.103

[37] W. J. Lee, H. J. Jung, J. H. Yoon, and S. H. Choi, "Analysis of variance for fuzzy data based on permutation method," International Journal of Fuzzy Logic and Intelligent Systems, vol. 17, no. 1, pp. 43-50, 2017. https://doi.org/10.5391/IJFIS.2017.17.1.43

[38] S. M. Taheri and G. Hesamian, "Non-parametric statistical tests for fuzzy observations: fuzzy test statistic approach," International Journal of Fuzzy Logic and Intelligent Systems, vol. 17, no. 3, pp. 145-153, 2017. https://doi.org/10.5391/IJFIS.2017.17.3.145

[39] H. Lee and S. Kim, "Black-box classifier interpretation using decision tree and fuzzy logic-based classifier implementation," International Journal of Fuzzy Logic and Intelligent Systems, vol. 16, no. 1, pp. 27-35, 2016. https://doi.org/10.5391/IJFIS.2016.16.1.27

[40] J. Yin, H. Sun, J. Yang, and Q. Guo, "Comparison of K-means and fuzzy c-means algorithm performance for automated determination of the arterial input function," PLoS One, vol. 9, no. 2, article no. e85884, 2014. https: //doi.org/10.1371/journal.pone.0085884

[41] R. J. Hathaway, J. C. Bezdek, and Y. Hu, "Generalized fuzzy c-means clustering strategies using Lp norm distances," IEEE Transactions on Fuzzy Systems, vol. 8, no. 5, pp. 576-582, 2000. https://doi.org/10.1109/91.873580
[42] M. Dorigo and S. Thomas, "The ant colony optimization metaheuristic: algorithms, applications, and advances," in Handbook of Metaheuristics. Boston, MA: Springer, 2003, pp. 250-285.

[43] J. Kennedy and R. Eberhart, "Particle swarm optimization," in Proceedings of the International Conference on Neural Networks, Perth, Australia, 1995, pp. 1942-1948. https: //doi.org/10.1109/ICNN.1995.488968

[44] X. S. Yang, "A new metaheuristic bat-inspired algorithm," in Nature Inspired Cooperative Strategies for Optimization. Heidelberg: Springer, 2010, pp. 65-74, 2010.

[45] K. B. Kim and D. H. Song, "Automatic intelligent asymmetry detection using digital infrared imaging with $\mathrm{k}$ means clustering," International Journal of Fuzzy Logic and Intelligent Systems, vol. 15, no. 3, pp. 180-185, 2015. https://doi.org/10.5391/IJFIS.2015.15.3.180

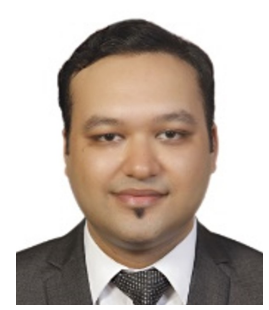

Rajan Gupta is a Research and Analytics Professional. He has done his PhD (Information Systems) from Department of Computer Science, University of Delhi, INDIA. His area of interest includes EGovernance, Public Information Systems, Multimedia Data processing, Data Mining and Data Analytics. He has over 50 publications at various national and international forums in the form of books, book chapters, journal papers, conference papers and articles.

E-mail: guptarajan2000@gmail.com

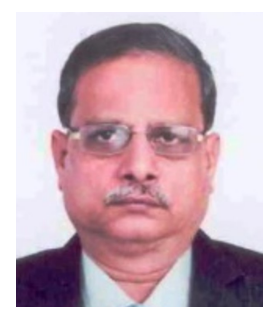

Sunil Kumar Muttoo is Professor at Department of Computer Science, University of Delhi, INDIA. He received his $\mathrm{PhD}$ in Coding Theory and M.Tech. in Computer Science and Data Processing from IIT, Kharagpur. His areas of interest include Information Hiding, Coding Theory and E-Governance. He has over 100 publications at national and international forums.

E-mail: drskmuttoo@gmail.com 


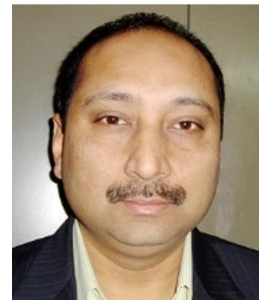

Saibal K. Pal is Senior Scientist with Scientific Analysis Group Lab, DRDO - Government of India. He received his $\mathrm{PhD}$ in Computer Science from University of Delhi, INDIA. His area of interest includes Information \& Network Security, Computational Intelligence, Information Systems and EGovernance. He has more than 200 publications at various forums.

Email: skptech@yahoo.com 